\title{
Can climate policy enhance sustainability?
}

\section{Lorenza Campagnolo, Carlo Carraro, Marinella Davide, Fabio Eboli, Elisa Lanzi \& Ramiro Parrado}

\section{Climatic Change}

An Interdisciplinary, International Journal Devoted to the Description, Causes and Implications of Climatic Change

\section{ISSN 0165-0009}

Climatic Change

DOI 10.1007/s10584-016-1701-6

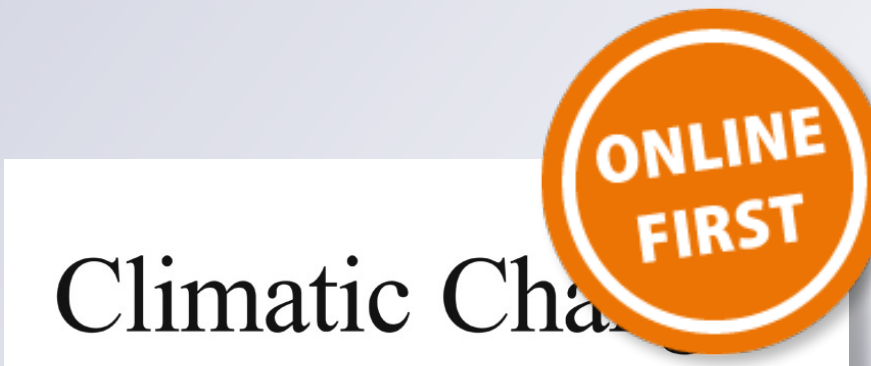

An Interdisciplinary, International Journal Devoted to the Description, Causes and Implications of Climatic Change Editors: MICHAEL OPPENHEIMER GARY YOHE

Volume 136- Nos, 3-4 - June 2016

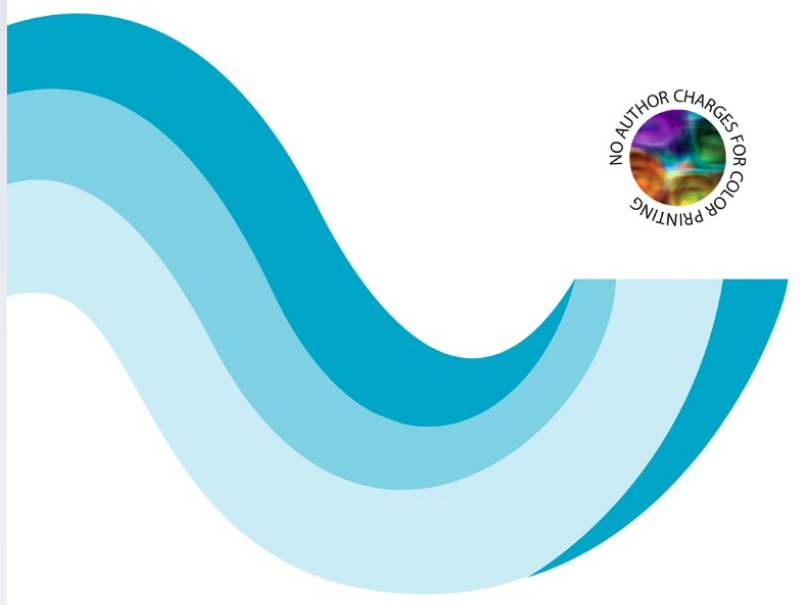


Your article is protected by copyright and all rights are held exclusively by Springer Science +Business Media Dordrecht. This e-offprint is for personal use only and shall not be selfarchived in electronic repositories. If you wish to self-archive your article, please use the accepted manuscript version for posting on your own website. You may further deposit the accepted manuscript version in any repository, provided it is only made publicly available 12 months after official publication or later and provided acknowledgement is given to the original source of publication and a link is inserted to the published article on Springer's website. The link must be accompanied by the following text: "The final publication is available at link.springer.com". 


\title{
Can climate policy enhance sustainability?
}

\author{
Lorenza Campagnolo ${ }^{1}$ - Carlo Carraro ${ }^{2}$. \\ Marinella Davide $^{2}$ - Fabio Eboli ${ }^{1}$ - Elisa Lanzi $^{3}$. \\ Ramiro Parrado ${ }^{1}$
}

Received: 20 December 2013 / Accepted: 18 May 2016

(C) Springer Science+Business Media Dordrecht 2016

\begin{abstract}
Implementing an effective climate policy is one of the main challenges for the future. Curbing greenhouse gas emissions can prevent future irreversible impacts of climate change. Climate policy is therefore crucial for present and future generations. Nonetheless, one may wonder whether future economic and social development could be harmed by climate policy. This paper addresses this question by examining recent developments in international climate policy and considering different levels of cooperation that may arise in light of the outcomes of the Conference of the Parties held in Doha. The paper analyses how various climate policy scenarios would enhance sustainability and whether there is a trade-off between climate policy and economic development and social cohesion. This is done by using a new comprehensive indicator, the FEEM Sustainability Index (FEEM SI), which aggregates several economic, social, and environmental indicators. The FEEM SI is built into a recursivedynamic computable general equilibrium model of the world economy, thus offering the possibility of projecting all indicators into the future and of delivering a perspective assessment of sustainability under different future climate policy scenarios. We find that the environmental component of sustainability improves at the regional and world level thanks to the implementation of climate policies. Overall sustainability increases in all scenarios since the economic and social components are affected negatively yet marginally. This analysis does not include explicitly climate change damages and this may lead to underestimating the benefits of policy
\end{abstract}

Electronic supplementary material The online version of this article (doi:10.1007/s10584-016-1701-6) contains supplementary material, which is available to authorized users.

Lorenza Campagnolo

lorenza.campagnolo@feem.it

1 Fondazione Eni Enrico Mattei (FEEM) and Fondazione CMCC - Centro Euro-Mediterraneo sui Cambiamenti Climatici, Venice, Italy

2 Fondazione Eni Enrico Mattei (FEEM), Fondazione CMCC - Centro Euro-Mediterraneo sui Cambiamenti Climatici and $\mathrm{Ca}$ ' Foscari University of Venice, Venice, Italy

3 Fondazione Eni Enrico Mattei (FEEM), Venice, Italy 
actions. If the USA, Canada, Japan and Russia did not contribute to mitigating emissions, sustainability in these countries would decrease and the overall effectiveness of climate policy in enhancing global sustainability would be offset.

\section{JEL Classification Q54·Q56·C68}

\section{Introduction}

Designing and implementing effective climate policies is often controversial because of the costs and efforts that may compromise future growth. International negotiations under the United Nations Framework Convention on Climate Change (UNFCCC) have walked a long way. After two decades of negotiations, the last Conference of the Parties (COP), held in Paris at the end of 2015, made a crucial step towards the achievement of globally coordinated climate action after 2020. However, the variety of policy options that could emerge from the current fragmented international landscape highlights the need to analyse the impacts of different policy scenarios looking not only at policy costs, but also at implications on sustainability.

This paper aims at assessing ancillary costs and benefits of climate policies, extending climate policy assessment to include effects on sustainability indicators in an integrated framework. This is done by linking a set of sustainability indicators with a recursivedynamic general equilibrium model, and projecting them up to 2020 under a baseline and four policy scenarios. The indicators' values are then aggregated using a non-linear algorithm to compute the Fondazione Eni Enrico Mattei Sustainability Index - FEEM SI (Carraro et al. 2013). By using FEEM SI, it is possible to analyse whether climate policies would help enhancing sustainability or, rather generate a trade-off with economic and social development.

The remainder of this paper is structured as follows. Section 2 briefly describes the current international climate policy context. Section 3 introduces the FEEM SI framework. Section 4 describes and analyses four climate policy scenarios, along with the likely impacts on sustainability. Section 5 concludes.

\section{International climate policy context}

In 1997, the Kyoto Protocol committed most industrialised nations and some economies in transition (Annex I Parties) to reduce overall emissions of greenhouse gases (GHGs) by $5.2 \%$ below 1990 levels between 2008 and 2012 (UNFCCC 2008). Subsequent negotiations, aimed at establishing mitigation commitments after 2012, were characterised by strong disagreement among countries, involving in particular the differentiation between Annex I and non-Annex I Parties' commitments.

In addition, the Kyoto Protocol did not reach enough international consensus to achieve the abatement level necessary to mitigate future climate change. If governments do not take further action to stabilise GHG concentration in the atmosphere, the average temperature by the end of this century may increase between $1.5^{\circ} \mathrm{C}$ and $4.8^{\circ} \mathrm{C}$ (Clarke et al. 2014). Further, delaying policy action will likely raise mitigation costs (Riahi et al. 2015).

At the end of COP-15 in 2009, the "Copenhagen Accord" (UNFCCC 2009) did not manage to reach the expected outcome but launched a pledge-and-review process involving 
both developed and developing countries. In this context, major emitting nations submitted an emission reduction plan (all Annex I and 39 non-Annex I countries, including China and India) (UNFCCC 2011a, 2011b).

However, little progress was made until 2011, when COP-17 in Durban launched a new negotiation stream with the objective to develop a new legal instrument applicable to all Parties, to be adopted by 2015 and to come into force in 2020 (UNFCCC 2011c). One year after, COP-18 in Doha finally established a second Kyoto commitment period (2013-2020), even though not all countries joined this effort: Canada, Japan and Russia officially declared they did not intend to commit for a second period, while the US confirmed that they would not join the Kyoto Protocol.

The adoption of the long-awaited Paris Agreement in 2015, which allows each country to determine mitigation action at national level, officially proposed a bottom-up approach also for the post-2020 period. Before the new agreement becomes operative in 2020, the action in the coming years will rely on the second Kyoto commitment period for the few countries that adopted it, and on the voluntary pledges for the others.

Another important milestone for 2015, closely intertwined with climate policy ambitions, is the adoption by UN General Assembly of the 2030 Agenda for Sustainable Development (UN 2015) setting 17 Sustainable Development Goals (SDGs) to be achieved worldwide by 2030 by means of a global strategy. The dimensions considered by SDGs include poverty reduction, sustainable economic growth, environment preservation, and climate mitigation commitments as well. The two deals signed in 2015 constitute a landmark calling to join efforts for the achievement of a sustainable future.

\section{Sustainability in a general equilibrium framework}

Sustainability is a complex and multi-faceted concept embodying environmental, economic and social dimensions (WCED 1987). A valid tool to measure sustainability is a set of indicators (Parris and Kates 2003; Kates et al. 2005; Singh and Gupta 2009), given their synthetic properties, as well as their role in supporting policymaking and in facilitating public communication. The indicators' aggregation procedure is more controversial. However, an index built with a transparent aggregation methodology and complementary to its single components can summarise a wide range of information to facilitate policy design, assessment and implementation.

FEEM SI ${ }^{1}$ summarises the three main components of sustainability (economy, society and environment) which, in turn, result from the aggregation of 19 theme-specific indicators from widely used international databases (Commission on Sustainable Development of the United Nations, EU Sustainable Development Strategy, and World Development Indicators from World Bank). Figure 1 illustrates the tree structure of FEEM SI.

FEEM SI builds on the recursive-dynamic computable general equilibrium (CGE) model ICES (Parrado and De Cian 2014; Eboli et al. 2010), which represents a constraint for indicator selection but at the same time provides a platform to analyse future sustainability scenarios in a coherent framework. For this analysis, ICES yields results up to 2020, representing major countries as well as macro regions, and 17 economic sectors. ICES is characterised by $n$ costminimising firms, a representative household maximising utility, and the government in each

\footnotetext{
${ }^{1}$ A more detailed description of FEEM SI and the general equilibrium model ICES is available in the Supplementary material, while a complete overview of the FEEM SI methodology is in Carraro et al. (2013) and Carraro et al. (2011).
} 


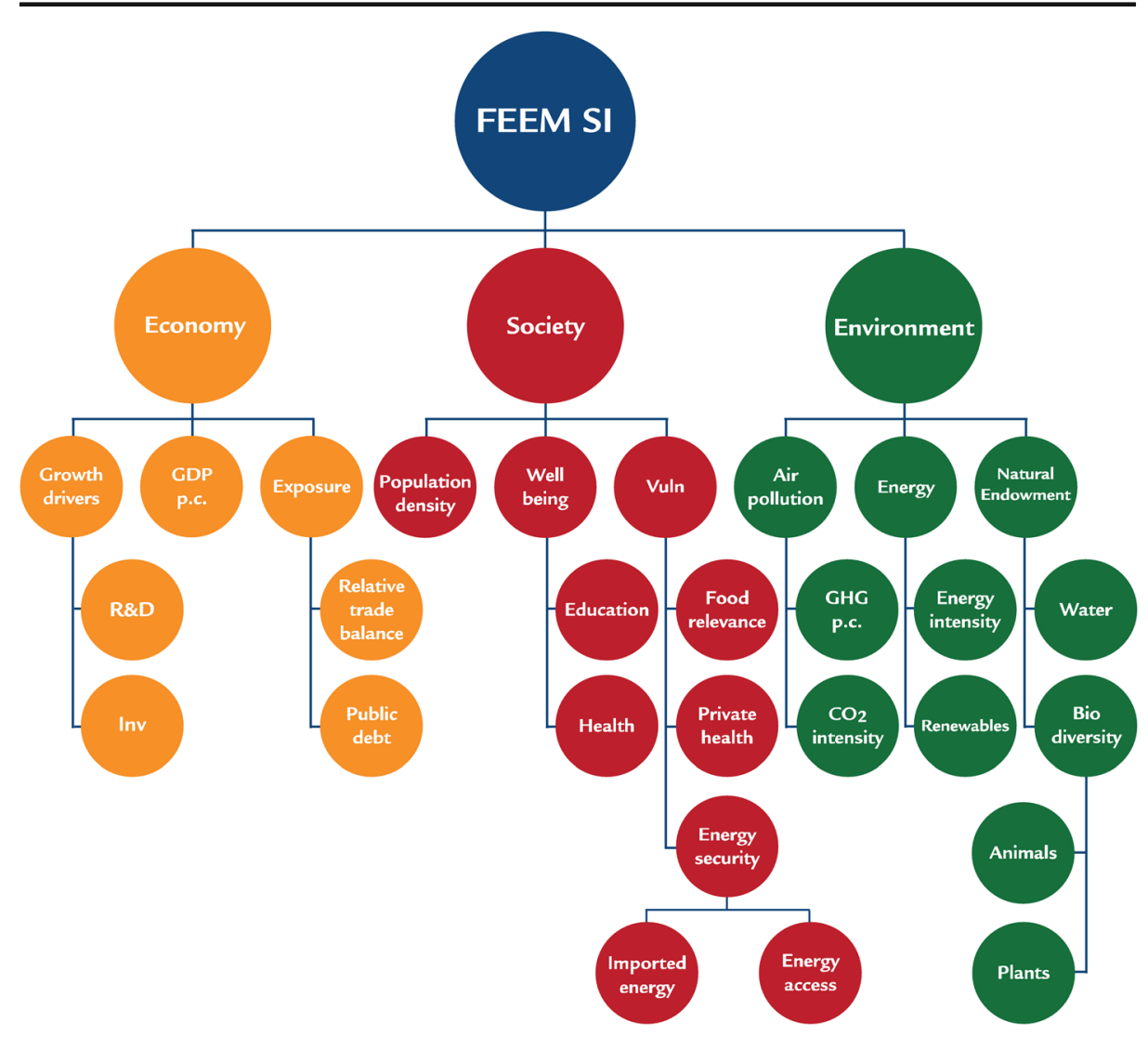

Fig. 1 FEEM SI indicator tree

region. Its dynamics depend on endogenously determined capital and foreign debt as well as exogenous assumptions on productivity and population changes (IMF 2010; World Bank 2010; IEA 2010).

CGE models can bring added value to the assessment of sustainability thanks to their flexible structure and the trade-off among different components they can capture. This is evident in a policy context, where an intervention in one country also influences other countries (not undertaking any policy) through trade relations and international spillovers (Boehringer and Loeschel 2004).

To better capture all sustainability dimensions (in addition to the economic one), ICES was enhanced with satellite databases, a more detailed sectoral aggregation (Research and Development, education, private and public health, and renewables) and additional variables (water volumes, biodiversity loss, and energy access). The projections for these additional variables from external databases are derived linking them to endogenous variables in the model: demand of water services by agriculture, industry and households in the case of water volumes, $\mathrm{CO}_{2}$ concentration in the case of biodiversity loss and gap from OECD average GDP per capita for energy access. 
ICES computes indicators for each country and simulation year. These are normalised to a common unit through target-oriented benchmarking functions, and weighted using experts' evaluations over a decision tree following the structure of Fig. 1. These subjective weights cannot be seen as representative of a population given the low sample size ( 20 experts $\left.^{2}\right)$. The low variance in experts' valuations and a further aggregation process (the metric distance method) allow deriving some "consensus weights". FEEM SI is computed combining the normalised indicators and the "consensus weights" through the Choquet integral (De Waegenaere and Wakker 2001; Murofushi et al. 1994; Cruciani et al. 2014). Despite the controversy regarding the aggregate indices due to subjectivity in weighting and the inevitable loss of information, FEEM SI is a valid tool to communicate messages to policymakers and general public, but it has always to be judged along with the pool of underlying indicators. ${ }^{3}$

Therefore, FEEM SI is an innovative policy-oriented sustainability index relying on a large database, capturing the trade-offs between different indicators and offering an ex-ante and policy-dependent assessment of sustainability.

\section{Emission abatement scenarios}

We run four mitigation scenarios starting in 2010 with the objective to assess possible outcomes of autonomous and coordinated efforts to curb GHG emissions by $2020^{4}$ :

1. Low pledges (global ITS) scenario: the low abatement pledges submitted under the Copenhagen Accord are effective for a set of leading regions, from both Annex I and Annex II (Table 1, second column). This scenario envisions a global international emission trading scheme (ITS), excluding China and India, which achieve their targets through a domestic carbon tax.

2. High pledges (global ITS) scenario: considers the high Copenhagen pledges (Table 1, fourth column) through a global ITS, except China and India implementing a domestic carbon tax.

3. Low pledges (EU ETS) scenario: only the European Union (EU27) is involved in a cooperative action adopting the European Emission Trading System (ETS); all other countries achieve their targets unilaterally with a domestic carbon tax.

4. Post-Doha scenario: considers the low Copenhagen pledges and the possible evolution after COP-18. US, Canada, Japan and Russia stay out of climate action until 2020; the US remain committed to their position to not join the Kyoto Protocol; Canada officially withdrew from the Kyoto Protocol and, consequently, will not take part in the second commitment period; Japan ${ }^{5}$ and Russia also confirmed they will not participate in the second committing period under the Protocol. EU-27 achieves the low Copenhagen pledges, using the ETS, while other countries achieve this through a carbon tax.

\footnotetext{
${ }^{2}$ We sent questionnaires to 60 experts. Among all responses we selected only those complete and noncontradictory.

${ }^{3}$ The following are well-known examples: Human Development Index (UNDP 2015), Environmental Performance Index (Hsu et al. 2016), Wellbeing Index (Prescott-Allen 2001), Global Gender Gap Index (World Economic Forum 2013) and OECD Better Life Index (OECD 2014).

${ }^{4}$ The analysis considers only $\mathrm{CO}_{2}$ as the main source of GHGs emissions from fossil fuels combustion.

${ }^{5}$ The decision to phase out nuclear power, undertaken by the Japanese government after the Fukushima disaster in 2011, will likely make future emission reduction more challenging without a large deployment of renewable energy technologies (IGES 2012).
} 


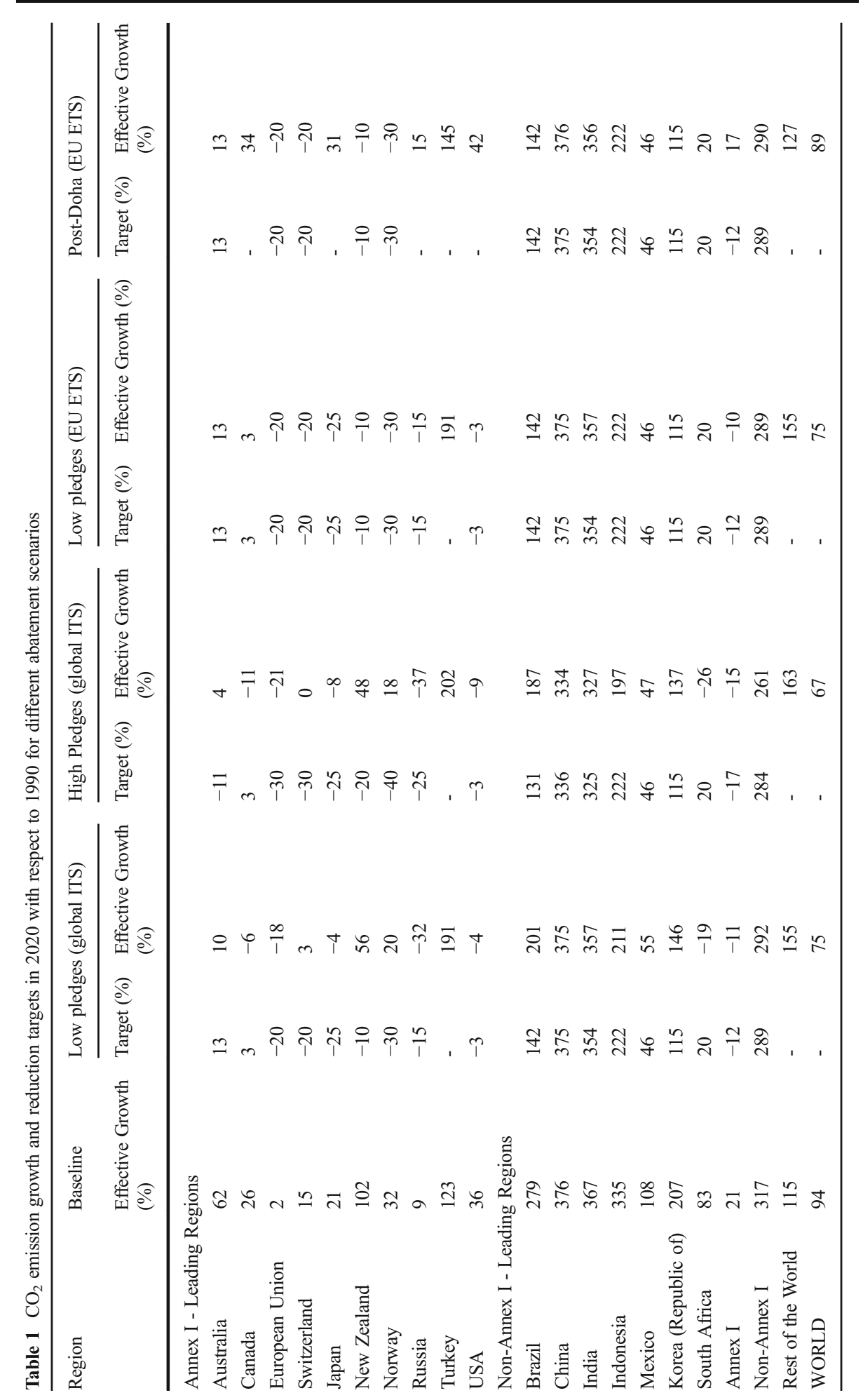




\subsection{Targets and effective growth in the abatement scenarios}

The outcome of different climate policies on $\mathrm{CO}_{2}$ emission levels is evaluated compared to a Baseline. This scenario has been built following IMF (2010) economic projections, and it does not include any intervention to control $\mathrm{CO}_{2}$ accumulation in the atmosphere. In the Baseline, global emissions almost double by 2020 , compared to the 1990 , with a growth of $94 \%$ (Table 1, first column).

Table 1 summarises the effective growth of $\mathrm{CO}_{2}$ emissions in each leading region of Annex I and non-Annex I, and an aggregate value for the Rest of the World ${ }^{6}$ according to the targets and policy mechanisms characterising the four climate policy scenarios described above.

In the Low pledges (global ITS) scenario, many Annex I countries show higher emission growth with respect to their targets. Russia, Canada and South Africa, with lower abatement costs, accomplish higher abatement and sell permits to other countries. Emission growth in 2020 with respect to 1990 is $+75 \%$. The overall outcome of this scenario is a reduction of emissions of $10 \%$ compared to the baseline, where Annex I countries contribute with $-26 \%$ of $\mathrm{CO}_{2}$ emissions and non-Annex I countries contribute with $-6 \%$. The Rest of the World increases by $18 \%$ their $\mathrm{CO}_{2}$ emissions, raising the issue of carbon leakage.

The High pledges (global ITS) scenario leads to a total additional abatement of $14 \%$ in 2020 compared to the baseline (+67\% with respect to 1990 levels), which translates into $\mathrm{a}-30 \%$ for Annex I, $-13 \%$ for non-Annex I and $+22 \%$ for Rest of the World. The stricter targets decrease emission levels, with highest efforts in Annex I countries and a consequent higher leakage effect in the Rest of the World.

In the Low pledges (EU ETS) scenario the EU27 is no longer able to purchase emission permits from other countries and must comply with the $-20 \% \mathrm{CO}_{2}$ mitigation target, instead of the observed $-18 \%$ of the Low pledges (global ITS) scenario.

In the last scenario, Post-Doha (EU ETS), global $\mathrm{CO}_{2}$ emission growth with respect to 1990 is close to the baseline ( $+89 \%$ ). The EU persists in achieving the $-20 \%$ target, whereas, the rest of the Annex I countries increase their emissions ( $+34 \%$ with respect to 1990). The non-Annex I aggregate presents similar results to the Low pledges (EU ETS) scenario $(+29 \%$ with respect to 1990) and carbon leakage slightly decreases in the Rest of the World (17\% with respect to 1990).

Although in 1990 Annex I countries emit more than the non-Annex I aggregate, the situation is reversed in all policy scenarios for 2020. The Rest of the World emissions are negligible in 1990 , but represent nearly $20 \%$ of the global $\mathrm{CO}_{2}$ level in the 2020 baseline and tend to increase in all scenarios except the Post-Doha one. The Rest of the World shows a leakage effect, which increases with more ambitious pledges and a lower geographical coverage of emission trading.

Implementing mitigation policies implies direct and indirect mitigation costs. As expected, direct costs increase with the stringency of mitigation targets. ${ }^{7}$ Indirect effects result from competitive interactions of economic activities. This latter component can be measured through the variation of GDP in 2020, with respect to the baseline. Figure 2 shows GDP in 2004 trillion US\$, which helps to assess the magnitude of climate policy cost.

\footnotetext{
${ }^{6}$ Rest of the World includes all countries not joining the Convention and few countries which are a part of the Convention but are included in a macro-region because of modelling purposes.

${ }^{7}$ In the Low pledges (global ITS) scenario the $\mathrm{CO}_{2}$ emission price is 89 US\$ per Tons of $\mathrm{CO}_{2}$ for all countries participating in the Kyoto Protocol (excluding China and India); in the High pledges (global ITS) scenario, it increases to 109 US\$. When introducing the ETS for the sole European market and considering only the low pledges (Low pledges, $\boldsymbol{E} \boldsymbol{U} \boldsymbol{E}$ TS), the carbon price remains high (98 US\$/T CO $\mathrm{C}_{2}$ ). In the Post-Doha scenario, the price decreases to $73 \mathrm{US \$} / \mathrm{T} \mathrm{CO}_{2}$.
} 


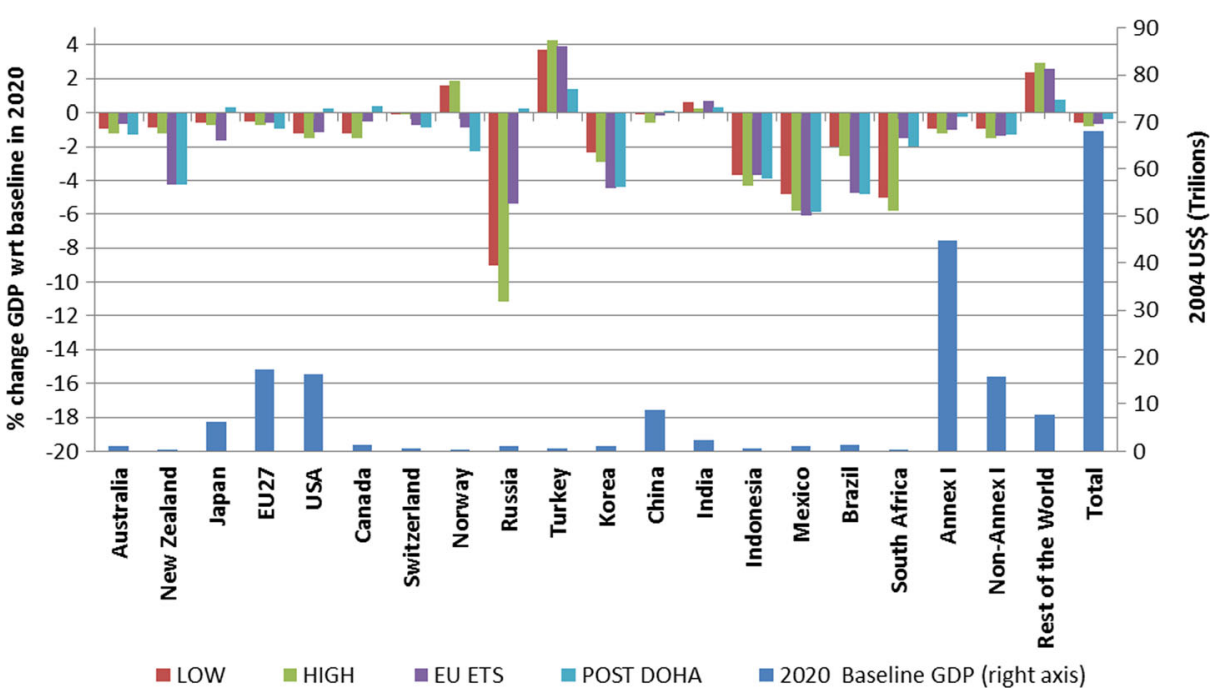

Fig. 2 GDP in 2020 (baseline) and the indirect costs of different abatement efforts

GDP loss is higher with more ambitious pledges. However, a more drastic change occurs when fewer countries partecipate to emission trading. Countries such as New Zealand, Japan, Norway, Korea, Mexico and Brazil pay the rigidity of the carbon tax instrument. The PostDoha scenario determines an increase of GDP for Japan, Canada, USA and Russia, since they have no pledges. The other economies experience a generalised GDP loss comparable to the high pledge scenario. The only exceptions are Turkey and the Rest of the World, which do not have a target but have a lower leakage effect in this scenario. Figure 2 shows that GHG mitigation is extremely costly for Russia. GDP loss in percentage change is higher for nonAnnex I countries than for Annex I.

These climate mitigation strategies determine an overall GDP loss of between 0.4 and $0.8 \%$ of 2020 's World GDP. These costs are in line with the recent literature. For example, the LIMITS project inter-model comparison pinpoints a global GDP loss in the range of 0.34 $0.40 \%$ in the case of a weak climate policy and $0.53-0.79 \%$ under a stringent climate policy (Kriegler et al. 2013). ${ }^{8}$

An important caveat is that the baseline scenario does not include the costs of inaction and the consequent needs to adapt to climate change. These have been extensively assessed in the literature (for recent reviews see IPCC 2014 and OECD 2015). Recent studies have shown that mostly developing countries will have negative consequences due to climate change while high latitude countries could experience some benefits (Dellink et al. 2014; Bosello and Parrado 2014). Mitigation efforts will also produce benefits from reduced climate impacts which could also offset mitigation costs depending on the country. This is an important point that must be bore in mind when analysing climate policies since, as we will discuss later, it may lead to underestimating the benefits of policy actions. ${ }^{9}$

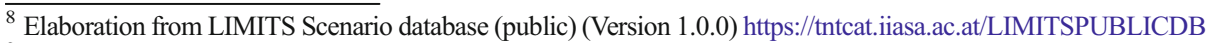

${ }^{9}$ Including these costs in the present analysis is difficult because the methodology requires an ensemble of several models contributing to an integrated assessment which is out of scope of the paper. The alternative would be to use impact and damage functions related to global warming but these stylised reduced forms are not available yet for the sectors, countries and macro-regions considered in this study.
} 


\subsection{Sustainability under different climate mitigation policies}

We now consider the effects of climate policy on the economic, social and environmental variables included in the model using FEEM SI, which has been calculated for each region and for the World as an aggregate (Fig. 3).

In the baseline, World's sustainability decreases until 2017 and then experiences a feeble growth thanks to the economic recovery, coupled with a rise in environmental sustainability (carbon and energy intensity indicators). All policy scenarios determine an improvement of sustainability with respect to the baseline, which is negligible in the Post-Doha scenario but higher in the other scenarios. The stricter the climate policy, the higher the sustainability achieved.

As shown in panel a) of Fig. 3, the Low pledges (global ITS / EU ETS) scenarios lead to a less drastic drop in sustainability, thanks to the improvement of environmental sustainability which balances the negative performance in the economic and social dimensions. At global level, the direct cost of climate policy in terms of GDP is insignificant. However, a more ambitious climate policy determines a higher drop in the economic pillar of sustainability. In particular, public debts increase due to a reduction in governments' revenues, driven by a domestic output shrinkage. The social pillar is also affected due to the contraction of available resources for education and health expenditures. There is a crowding out effect in public budgets when devoting resources to mitigation initiatives. The High pledges (EU ETS) scenario promotes the best outcome for sustainability, especially after 2017. Furthermore,

a) Overall Sustainability

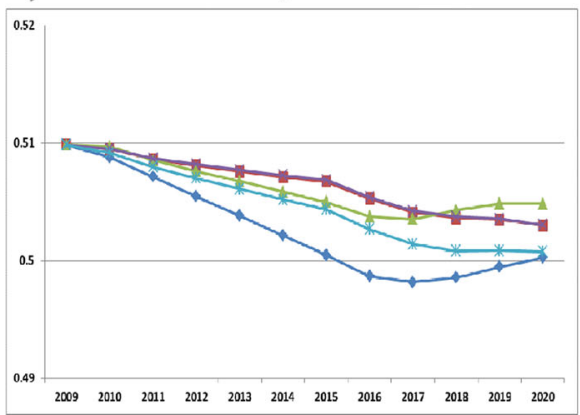

c) Social Sustainability

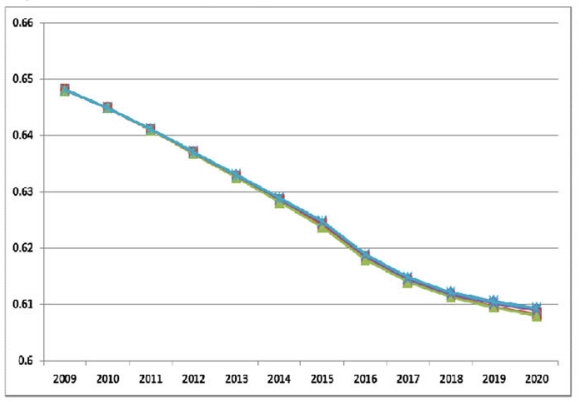

b) Economic Sustainability

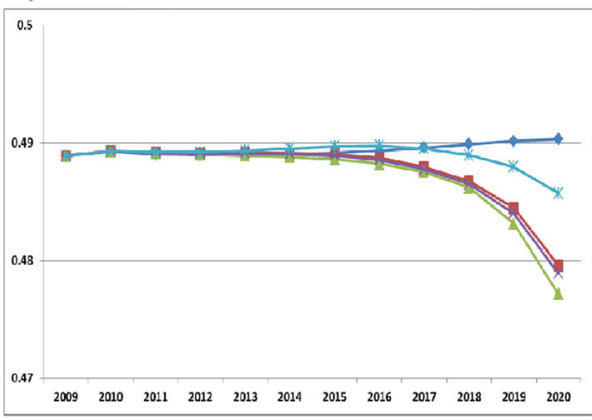

d) Environmental Sustainability

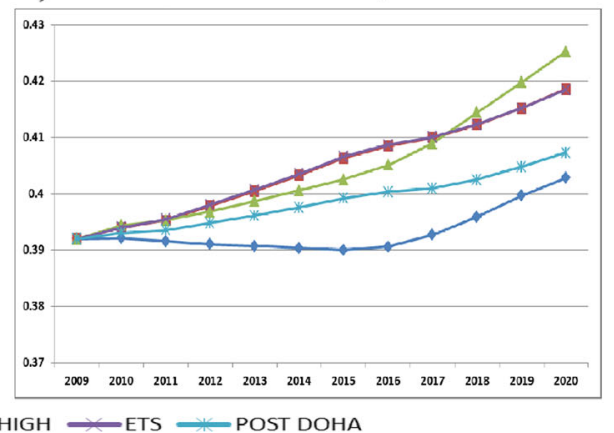

Fig. 3 Values of FEEM SI and sustainability pillars at world level 
whereas results in the economic and social pillars are only slightly lower compared to the low pledges scenarios, the benefits to the environmental dimension of sustainability are significant.

Figure 4 shows a consistent increase in the environmental component more than offsetting the decrease in the economic and social ones, leading to overall higher sustainability (with respect to the baseline). ${ }^{10}$ More ambitious mitigation targets would lead to a more sustainable World in 2020. Further, the Post-Doha scenario shows a drastic contraction of the benefit for environmental sustainability and a related reduction of economic losses, which determine an overall sustainability close to the baseline one.

It is important to recall the fact that this analysis does not factor in the costs of inaction on climate change, therefore underestimating benefits of mitigating climate change. If we included these on the baseline, sustainability pillars should report lower scores due to negative effects of climate change (e.g. lower economic output in most regions, increasing health care needs, a more deteriorated environment). Consequently, benefits of climate policies would be higher due to a greater improvement in all sustainability pillars.

Figure 5 shows detailed results for overall sustainability for four macro-regions: European Union, Rest of Annex I (excluding EU27), non-Annex I and Rest of the World. Most of EU27 countries see an improvement of their sustainability level between 1 and $2 \%$. Poland and Rest of EU are most positively affected by mitigation policies, achieving the highest emissions reduction among European countries at a low economic cost (they benefit from trading in the permit market). For Benelux and France, the benefit on the environmental pillar is nearly offset by economic and social losses.

In the Rest of Annex I aggregate, which includes the four non-committing countries in the Post-Doha scenario, the lack of a mitigation policy implies a lower sustainability than in the baseline scenario for Japan, Russia and USA or the replication of the baseline results in the case of Canada. Turkey, belonging to Annex I but with no pledge, is the only country that reduces its sustainability level in all policy scenarios.

Regarding the Non-Annex I aggregate (Fig. 5, panel c), India is the only country negatively affected by climate policy. The target on emission intensity is not stringent for this country, therefore, environmental sustainability benefits only marginally from the implementation of the four policy scenarios, compared with a worsening situation in the economic and social pillars. Most of the other non-Annex I countries experience an improvement in their sustainability level in the Post-Doha scenario, since they comply with the abatement targets, without purchasing emission reduction permits as in the ITS scenarios. China is excluded from this pattern as it is hardly affected by mitigation interventions.

In the Rest of the World region and Turkey environmental deterioration plays a major role, reflecting a carbon leakage effect for countries without climate policies. Overall, the Rest of the World sees a stronger shrinking of their sustainability when mitigation is more ambitious and the leakage effect is larger.

Figure 6 illustrates in detail changes in sustainability for USA, Canada, Japan and Russia, Italy and Turkey. USA's economic and social pillars are largely unaffected in all climate policy scenarios. While GDP per capita remains unchanged, environmental sustainability increases

\footnotetext{
$\overline{10}$ This overall result depends on the subjective weights used in aggregating each component of the sustainability pillars. We acknowledge that aggregating such a heterogeneous set of indicators can be a questionable approach (Commission on the Measurement of Economic Performance and Social Progress (2009). However, our framework aims at capturing the essence of the concepts of sustainability as a synthesis of different dimensions and subjectivity.
} 


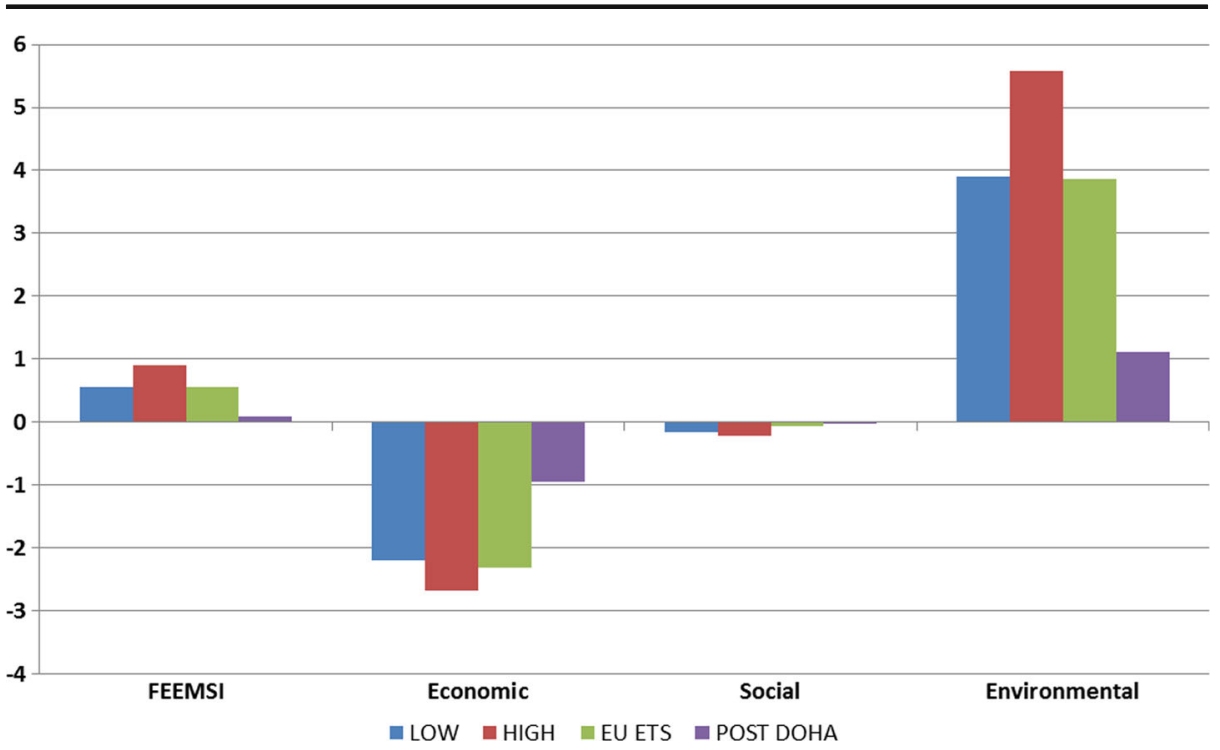

Fig. 4 Percentage changes in FEEM SI with respect to the baseline in 2020 (World level)

up to $45 \%$, thanks to mitigation policies. Moreover, in the Post-Doha scenario overall and environmental sustainability in the USA drop below baseline levels.

For Canada and Russia, phasing out mitigation pledges recreates the sustainability path of the baseline scenario; even if the economic pillar increases, the decrease in environmental sustainability offsets all economic benefits. Japan loses more than other countries in terms of overall sustainability, due to the drop in the environmental pillar.

\section{a) European Union}

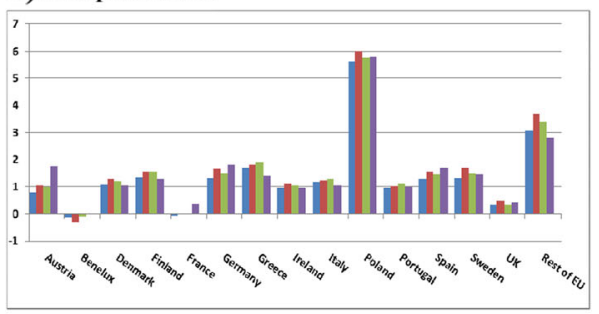

c) Non-Annex-I

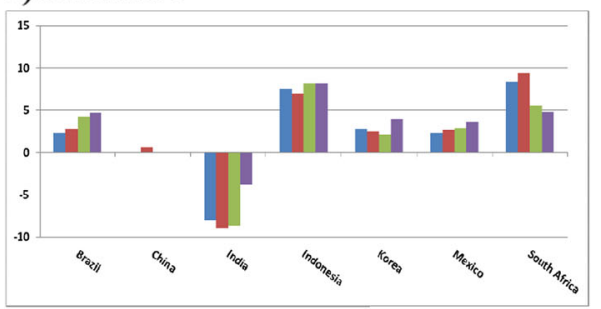

口LOW $\quad$ HIGH $\quad$ ETS $\quad$ POST DOHA

Fig. 5 Percentage changes in FEEM SI with respect to the baseline at 2020 by country b) Rest of Annex-I

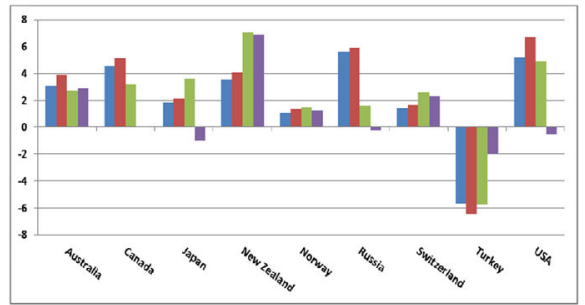

\section{d) Rest of the World}

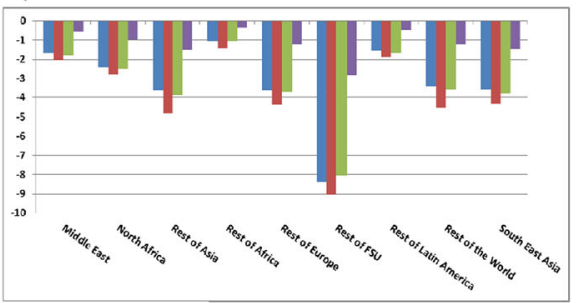


a) USA

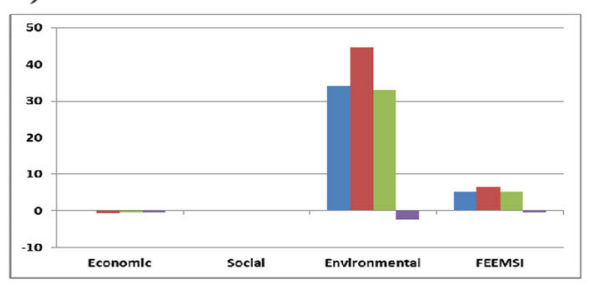

c) Japan

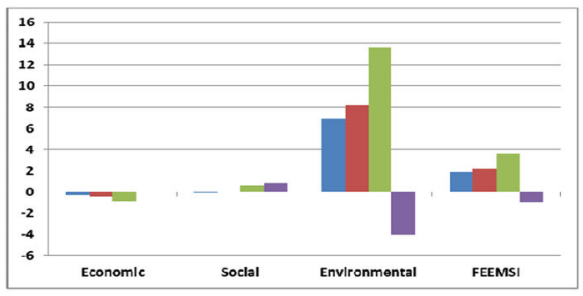

e) Italy

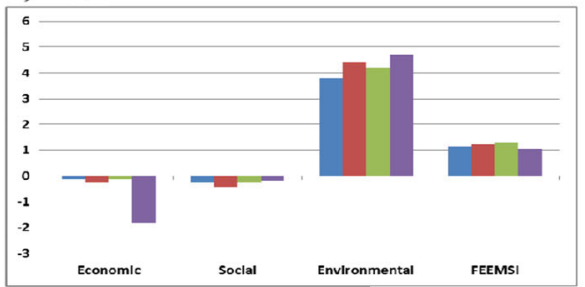

b) Canada

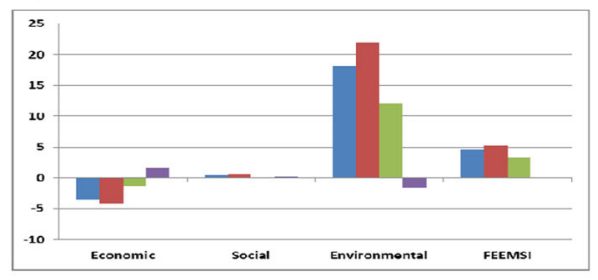

d) Russia

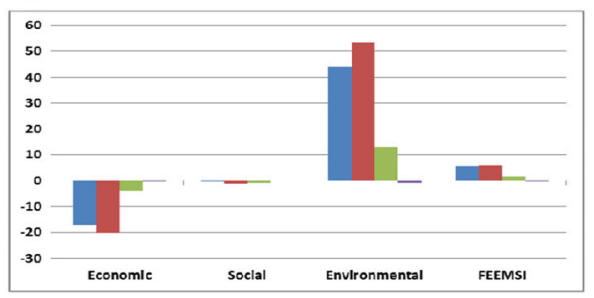

f) Turkey

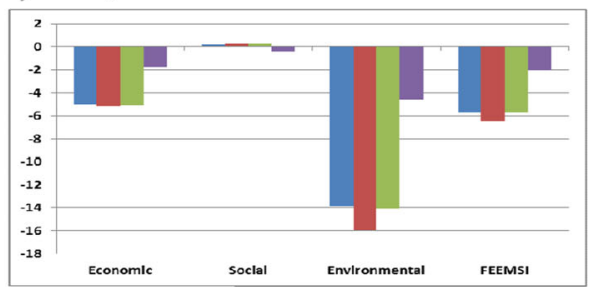

- LOW $\square$ HIGH $\square$ ETS $\square$ POST DOHA

Fig. 6 Percentage changes in FEEM SI and its components with respect to the baseline in 2020 for selected countries

These results offer additional proof of the beneficial effect of emission control on countries' sustainability. Benefits are higher with stricter abatement targets. Countries would not gain when they withdraw from their pledges. Even though the cost of climate policy is lower, the negative performance of environmental indicators is more relevant in terms of sustainability than the positive economic benefits, leading to lower sustainability levels than in the baseline.

\section{Conclusions}

This paper proposes extending climate policy assessments to comprise ancillary costs and benefits on economic, social and environmental dimensions within an integrated framework considering implications on sustainability. It is important to further analyse the relevance of climate policy and its role in addressing climate-related environmental issues, without harnessing economic and social development. The analysis focuses on the effects on sustainability of a range of climate mitigation scenarios, inspired by the current state of climate negotiations.

This assessment uses FEEM SI, which summarises the economic, social and environmental components of sustainability in a set of composite indicators. FEEM SI is built within a 
dynamic CGE model, allowing for scenario analysis, and thus, offering a useful instrument for evaluating climate policies and their impacts on future sustainability levels.

Our analysis illustrates that, despite the costs of meeting climate targets, sustainability is likely to increase thanks to the implementation of mitigation measures. The environmental component is affected positively, both at the regional and world levels. The economic and social components are less affected, even though negatively, and this loss rarely offsets the benefits. The more ambitious the pledges are, the more likely they will lead to higher performances of the environmental pillar and of overall sustainability. This analysis does not factor in the costs of inaction to climate change. Including them would show even more benefits on sustainability after implementing climate policies.

The most interesting insight stems from the analysis of the Post-Doha scenario, envisioning the non-commitment of Canada, USA, Japan and Russia. The lack of policy action leads to negative effects, at both the world and country levels. The four non-committing countries, which experience a benefit in both the High and Low pledges scenarios, loose their gains in the Post-Doha scenario, with a sustainability performance close to the one in the baseline scenario. These findings confirm that a no-climate-policy strategy would be costly and that mitigation efforts, even if fragmented, would contribute to increase sustainability.

Our results show how the cost of climate policy cannot be measured using only GDP. Climate policy has pervasive effects on economic, social and environmental variables. Analysing the underlying components of sustainability can be useful to improve the understanding of climate policy costs and benefits. The aggregation of these different elements into a set of composite indicators can help policymakers in comparing different scenarios and outcomes in order to establish priorities and adopting more informed decisions. Notwithstanding, a responsible assessment should not only rely on aggregated indexes, but also on underlying single indicators.

FEEM SI can be a useful tool in assessing future sustainability and the effects of policy measures. It can certainly be refined, for example increasing the number of experts used for the aggregation procedure. The adoption of the SDGs brings new opportunities to find innovative ways to assess sustainability in a policy evaluation context, to which our methodology can certainly contribute. The 2030 Agenda for Sustainable Development encourages the use of a broader range of indicators and extending the time frame of policy analysis. Future research will also consider more extensively climate change impacts on different sustainability dimensions, and introduce uncertainty underlying future socioeconomic scenarios.

Acknowledgments This paper is part of the research of the Climate Change Economic Impacts and Adaptation of the Fondazione Eni EnricoMattei. We would like to thank the reviewers for their helpful comments and suggestions.

\section{References}

Boehringer C, Loeschel A (2004) Measuring Sustainable Development: The Use of Computable General Equilibrium Models. Discussion Paper No. 04-14. Center for European Economic Research (ZEW), Mannheim

Bosello F, Parrado R (2014) Climate Change Impacts and Market Driven Adaptation: the Costs of Inaction Including Market Rigidities. FEEM Working Paper No. 64.2014

Carraro C, Campagnolo L, Cruciani C, Eboli F, Giove S, Lanzi E, Parrado R, Pinar M, Portale E (2011) FEEM SI Methodological report 2011. Available on line at: http://www.feemsi.org/documents/FEEM\%20SI\% 202011\%20Methodological\%20Report\%202011.pdf

Carraro C, Campagnolo L, Eboli F, Giove S, Lanzi E, Parrado R, Pinar M, Portale E (2013) The FEEM sustainability index: an integrated tool for sustainability assessment. In: Erechtchoukova M G et al. (eds.) 
Sustainability appraisal: quantitative methods and mathematical techniques for environmental performance evaluation. Springer-Verlag Berlin, Heidelberg

Clarke L, Jiang K, Akimoto K, Babiker M, Blanford G, Fisher-Vanden K, Hourcade J-C, Krey V, Kriegler E, Löschel A, McCollum D, Paltsev S, Rose S, Shukla P R, Tavoni M, van der Zwaan B C C, van Vuuren D P (2014) Assessing transformation pathways. In: Climate change 2014: mitigation of climate change. Contribution of working group III to the fifth assessment report of the intergovernmental panel on climate change [Edenhofer O, Pichs-Madruga R, Sokona Y, Farahani E, Kadner S, Seyboth K, Adler A, Baum I, Brunner S, Eickemeier P, Kriemann B, Savolainen J, Schlömer S, von Stechow C, Zwickel T, Minx J C (eds.)]. Cambridge University Press, Cambridge

Commission on the Measurement of Economic Performance and Social Progress (2009) Report of the commission on the economic and social progress. Available on line at: http:/www.stiglitz-sen-fitoussi.fr/documents/ rapport_anglais.pdf

Cruciani C, Giove S, Pinar M, Sostero M (2014) Constructing the FEEM sustainability index: a Choquet-integral application. Ecol Indic 39:189-202

De Waegenaere A, Wakker PP (2001) Nonmonotonic Choquet integrals. J Math Econ 36(1):45-60

Dellink R, Lanzi E, Chateau J, Bosello F, Parrado R, De Bruin K (2014) Consequences of Climate Change Damages for Economic Growth: A Dynamic Quantitative Assessment. OECD Economics Department Working Papers No. 1135. OECD Publishing, Paris, doi: 10.1787/5jz2bxb8kmf3-en

Eboli F, Parrado R, Roson R (2010) Climate change feedback on economic growth: explorations with a dynamic general equilibrium model. Environment and Development Economics Volume 15(5):515-533

Hsu A et al. (2016) 2016 environmental performance index. Yale University, New Haven Available: www.epi.yale.edu

IEA (2010) World energy outlook 2010. OECD/IEA, Paris

IGES (2012) Lessons learnt from the triple disaster in East Japan. IGES Policy Report No.2012-01. Institute for Global Environmental Strategies.

IMF (2010) Wold economic outlook 2010. International Monetary Found

IPCC (2014) Climate change 2014: impacts, adaptation, and vulnerability. Part A: global and sectoral aspects, contribution of working group II to the fifth assessment report of the intergovernmental panel on climate change [Field, C B, Barros, V R, Dokken, DJ, Mach, K J, Mastrandrea, M D, Bilir, T E, Chatterjee M, Ebi, K L, Estrada, Y O, Genova, R C, Girma, B, Kissel, E S, Levy, A N, MacCracken, S, Mastrandrea, P R, White, L L (eds.)]. Cambridge University Press, Cambridge 1132 pp.

Kates RW, Parris T, Leiserowitz A (2005) What is sustainable development? Goals, indicators, values and practice. Environment: Science and Policy for Sustainable Development 47(3):8-21

Kriegler E, Tavoni M, Aboumahboub T, Luderer G, Calvin K, De Maere G, Krey V, Riahi K, Rosler H, Schaeffer M, van Vuuren D (2013) What does the 2C target imply for a global climate agreement in 2020? The LIMITS study on Durban platform scenarios. Climate Change Economics 4(4)

Murofushi T, Sugeno M, Machida M (1994) Non-monotonic fuzzy measures and the Choquet integral. Fuzzy Sets Syst 64(1):73-86

OECD (2014) How's life? 2015: measuring well-being. OECD Publishing, Paris

OECD (2015) The economic consequences of climate change. OECD Publishing, Paris

Parrado R, De Cian E (2014) Technology spillovers embodied in international trade: intertemporal, regional and sectoral effects in a global CGE framework. Energy Econ 41(2014):76-89

Parris TM, Kates RW (2003) Characterizing and measuring sustainable development. Annu Rev Environ Resour 28(1):559-586

Prescott-Allen R (2001) The well-being of nations. Island Press, Washington, DC

Riahi K, Kriegler E, Johnson N, Bertram C, den Elzen M, Eom J, Schaeffer M, Edmonds J, Isaac M, Krey V, Longden T, Luderer G, Méjean A, McCollum D L, Mima S, Turton H, Van Vuuren D P, Wada K, Bosetti V, Capros P, Criqui P, Hamdi-Cherif M, Kainuma M, Edenhofer O. (2015) Locked into Copenhagen pledges implications of short-term emission targets for the cost and feasibility of long-term climate goals. Tech. For. Soc. Chang. 90 (PA) (2015) 8-23

Singh M, Gupta D (2009) An overview of sustainability assessment methodologies. Ecol Indic 9:189-212

UN (2015) Transforming our world: the 2030 Agenda for Sustainable Development United Nations 2015. United Nations. Available at https://sustainabledevelopment.un.org/post2015/transformingourworld/publication

UNDP (2015) Human Development Report 2015. United Nations Development Programme. Available at: http:// hdr.undp.org/sites/default/files/2015_human_development_report.pdf

UNFCCC (2008) The Kyoto Protocol, Unfccc.int. 2008-05-14. http://unfccc.int/kyoto_protocol/background/ items/3145.php. Retrieved 2009-05-21

UNFCCC (2009) Draft decision -/CP.15 Proposal by the President. Copenhagen Accord. Available at http:// unfecc.int/resource/docs/2009/cop15/eng/107.pdf

UNFCCC (2011a) Compilation of economy-wide emission reduction targets to be implemented by Parties included in Annex I to the Convention. Available at http://unfccc.int/resource/docs/2011/sb/eng/inf01r01.pdf 
UNFCCC (2011b) Compilation of information on nationally appropriate mitigation actions to be implemented by Parties not included in Annex I to the Convention. Available at: http://unfccc.int/resource/docs/2011/ awglca14/eng/inf01.pdf

UNFCCC (2011c) Decisions adopted by COP 17 and CMP 7. Available at: http://unfccc.int (accessed July 5, 2012) Available at http://unfccc.int

World Bank (2010) World development indicators - population, total. Available on line at: http://data.worldbank. org/indicator/SP.POP.TOT

World Commission on Environment and Development (WCED) (1987) Our common future. Published as annex to general assembly document a/42/427, development and international Co-operation: environment August 2, 1987. Retrieved, 2007.11.14

World Economic Forum (2013) The global gender gap report 2013. World Economic Forum 